(RESEARCH ARTICLE)

\title{
Acute and sub-acute toxicity of the aqueous extract of the stem bark of Rauwolfia vomitoria (Apocynaceae) in Wistar rats.
}

\author{
Youmbie Djanche Duplex Bonheur 1,*, Dzeufiet Djomeni Paul Désiré ${ }^{2}$, Kada Sanda Antoine ${ }^{1}$, Fotsing David 1 \\ and Dimo Théophile ${ }^{2}$ \\ ${ }^{1}$ Department of Biological Sciences, Faculty of Science, University of Bamenda P.O. Box 39 Bambili, Cameroon. \\ ${ }^{2}$ Department of Animal Biology and Physiology, Faculty of Science, University of Yaounde 1 P.0. Box 812, Yaounde, \\ Cameroon.
}

Publication history: Received on 15 December 2020; revised on 22 December 2020; accepted on 24 December 2020

Article DOI: https://doi.org/10.30574/wjarr.2020.8.3.0490

\begin{abstract}
The present study investigated the toxicological potential of the oral administration of the stem bark aqueous extract of $R$. vomitoria on the liver and kidney in rats. Acute oral toxicity study of the extract to a single dose of $2000 \mathrm{mg} / \mathrm{kg}$ was studied in 10 rats of both sexes. Sub -acute oral toxicity of aqueous extract of was carried out on 60 rats. We constituted 4 groups of 10 rats each (5 males and 5 females) which were orally administered 300,600, and $900 \mathrm{mg} / \mathrm{kg}$ of aqueous extract and control group received water. 2 group satellites (SAT) of 10 rats each ( 5 males and 5 females) in which one group (SAT $900 \mathrm{mg} / \mathrm{kg}$ ) was received orally $900 \mathrm{mg} / \mathrm{kg}$ of aqueous extract and another (SAT control) water. Serum blood was collected for biochemical and haematological parameters. The liver and kidney served for histological examination. No deaths of acute oral toxicity were recorded. In female rats, Aspartate Aminotransferase (ASAT) activity increased by $31.20 \%$ and Alamine Aminotransferase (ALAT) increased by $37.20 \%$. In male rats, only ALAT activity increased significantly by $35.37 \%$ compared to control. Haematological analysis revealed in male rats treated at the dose of $900 \mathrm{mg} / \mathrm{kg}$ an increase significant $(\mathrm{p}<0.001)$ level of white blood cells with $52.20 \%$, compared to control group. Histological examination of liver and kidney showed normal architecture. Aqueous extract has untoward effect on liver and kidney, could be considered non-toxic.
\end{abstract}

Keywords: Rauwolfia vomitoria; Toxicity; Liver; Kidney; Lungs

\section{Introduction}

Drugs of plant origin have served through the ages as the mainstay in the treatment of variety of diseases and preservation of human health. However, their general acceptability has been limited by lack of dose regiment and adequate toxicity data to evaluate their safety [1]. It is therefore necessary to investigate the toxicity of local medicinal plants usually employed by herbalists in treatment of diseases, especially now that there are proposals on the integration of traditional medicine in health care programs in most countries over the World [2]. Rauwolfia vomitoria is a medicinal plant which grows in the humid tropical secondary forests in Africa and it is used traditionally to treat a variety of ailments [3]. Extensive studies carried out on its chemical properties showed that this plant contains more than 50 active indole alkaloids, each possessing remarkable physiological and pharmacological activities [4]. A bioactive $ß$-carboline alkaloid, alstonine, present in the root and leaf were shown to have anti-cancer activity $[5,6]$ while the antipyretic effect of leaf extract has also been demonstrated [7]. The pharmaceutical derivatives are used mainly as antihypertensive and sedatives. Its sedative property is attributed to its ability to balance body response to stress and anxiety and to increase oxygen delivery to the brain [8]. Stem bark of Rauwolfia vomitoria was used to treat inflammation, pain and oxidative stress in rats $[9,10]$. Traditional medicinal uses of the roots are extensive, particularly

\footnotetext{
* Corresponding author: Youmbie Djanche Duplex Bonheur; Tel: 237677644983; youmbidjanche@gmail.com Department of Biological Sciences, Faculty of Science, University of Bamenda P.0. Box 39 Bambili, Cameroon.
} 
for their aphrodisiac, emetic, purgative, dysenteric, abortive and insecticidal properties [11]. Decoctions of the leaves of $R$. vomitoria have a powerful emetic effect and chopped leaves stewed with animal fat are applied to swellings [12]. The root is also brewed as a tea and used in humans to treat snakebite and cholera [13].

Traditional medicine practitioners believe that the herb is non-toxic but there are no adequate documented toxicity data to support this claim. As this herb continues to receive attention up to date, and more of its medicinal values discovered day by day, there is need to investigate the effects of its consumption on liver, kidney and lung function using animal model.

To search intoxicated organs, the present study was carried out to determine the biochemical, haematological and histological toxicity of aqueous extract of $R$. vomitoria stem bark in rats. In addition, search information on the safety of $R$. vomitoria. Indeed, provide guidance for selecting a safe dose of $R$. vomitoria in its use in traditional medicine.

\section{Material and methods}

\subsection{Biochemical parameter tests}

\subsubsection{Laboratry kits}

The chemical and reagents used in the present test were of analytical grade. The enzyme kits were obtained from Fortess Diagnostic, United Kingdom and Inmesco, Germany. Absorbances were read using Genesy20 spectrophotometer. The different kits and chemicals were used for the assessment of the tests of Alamine amino transferase (ALAT), Aspartate Amino tranferase (ASAT), Total bilirubine, Alkaline phosphatase (ALP), Creatinine, Total cholesterol, Triglyceride (TGY), High density lipoprotein (HDL)-cholesterol and Low density lipoprotein (LDL)-cholesrol.

\subsubsection{Measurement of total protein}

The total protein content in serum was determined by the method of Gornal in 1949[14]

\subsection{Haematological parameter tests}

The analysis of haematological parameters was carried out in the laboratory of Yaounde-Central-Hospital-Cameroon using a machine (Ham screen18, Haematology Analyser). This haematological analysis determined the amount of white blood cells, lymphocytes, monocytes, granulocytes, red blood cells, and the concentration of haemoglobin, haematocrit and platelets.

\subsection{Plant material}

\subsubsection{Plant collection and identification}

In accordance with our previous work, the fresh stem bark of $R$. vomitoria was collected in the month of Jun 2018 and identified $[9,10]$.

\subsubsection{Preparation of aqueous extract of $R$. vomitotia}

As described in our previous work, $3 \mathrm{~kg}$ of powder of $R$. vomitoria was obtained and $200 \mathrm{~g}$ was macerated in 7.5 liters of distilled water. The filtrate was evaporated and dark brown solid aqueous extract was obtained (Yield 6.67 \%). Given that the efficient dose was $300 \mathrm{mg} / \mathrm{kg}$ in our previous research, the doses of 300, 600 and $900 \mathrm{mg} / \mathrm{kg}$ were used for this study [15].

\subsection{Experimental animals}

Male and female Wistar rats (120-130 g) were used for the experiments $[9,10]$.

\subsection{Acute toxicity assessment}

The acute oral toxicity of aqueous extract of $R$. vomitoria was evaluated in Wistar rats according to the procedures outlined by the Organization for Economic Co-operation and Development [15].

Following the fasting period of 12 hours, the rats were weighted and the dose was calculated in the reference to the body weight. Volume of the extract given to the rat was $10 \mathrm{~mL} / \mathrm{kg}$ body weight. The crude extract was suspended in a vehicle (distilled water). For the main test, a single dose of $2000 \mathrm{mg} / \mathrm{kg}$ of the extract was administered orally to 5 rats 
of both sexes whereas the control group of 5 rats of both sexes received distilled water. Food was provided to rats approximately 3 to 4 hours after treatment [15]. The animals were observed $30 \mathrm{~min}$ after dosing, followed by hourly observation for 24 hours and once a day for the next 13 days. All observations systematically recorded with individual records being maintained for each animal. Surviving animals were weighted and visual observations of mortality, behavioral pattern, changes in physical appearance, injury, pain and signs of illness were conducted daily during the period [15].

\subsection{Sub-acute toxicity assessment}

Sub-acute toxicity was consisting of oral administration of substances for 28 days. The aqueous extract of $R$. vomitoria was evaluated for their sub-acute toxicity in Wistar rats. For this experiment, 60 rats were shared into 6 groups (I, II, III, IV, V, and VI) of 10 rats each as follows:

- Group I served as control group and was received distilled water $10 \mathrm{~mL} / \mathrm{kg}$.

- Groups II, III and IV received the aqueous extract of $R$. vomitoria at the doses of 300, 600 and $900 \mathrm{mg} / \mathrm{kg}$ respectively.

- Groups V and VI were called satellite (SAT) which means observation continues for 2 weeks to check any irreversible adverse arising from delayed toxicity. Then, group V was called SAT control and received distilled water whereas group VI was called SAT extract and received aqueous extract at the dose of $900 \mathrm{mg} / \mathrm{kg}$ (SAT E $900 \mathrm{mg} / \mathrm{kg})$.

At the end of 28 days of treatment and 42 days for satellite, animals were sacrificed, blood was collected into two type tubes: One with anti-coagulant ethylenediamine-tetraacetate (EDTA) was analysed immediately for haematological parameters. Another without anti-coagulant was centrifuged at $3000 \mathrm{rpm}$ at $4^{\circ} \mathrm{C}$ for $15 \mathrm{~min}$ to obtain the serum, which was stored at $-20^{\circ} \mathrm{C}$ until analysis for biochemical parameters.

\subsection{Hispathological study}

To study the liver, kidney and lungs under microscope, the tissues passed via many proceedings of fixation, dehydration, clearing, infiltration, embedding, section and stain. During fixation, liver, kidney and lung samples of control groups and those received highest dose $900 \mathrm{mg} / \mathrm{kg}$ were kept in $10 \%$ neutral formalin. After fixation, tissues have been dehydrated in different percentages of alcohol (75\%, $95 \%$ and $100 \%$ absolute), embedded in paraffin block and serially sectioned (5 $\mu \mathrm{m}$ size) using a microtome. Liver, kidney and lung sections were stained with Mayer hematoxylin eosin. The structure of liver, kidney and lung tissues after the treatment was observed using a microscope (Zeiss, Hallbermoos, Germany).

\subsection{Statistical analysis}

Results obtained in this study were analysed using Graph pad prism software version 5.03. The analysis consisted with one way analysis of variance (ANOVA) followed by bonfeeroni post-test. All data were presented as means \pm Standard Error Means (E.S.M). Statistical significance was considered at a level of $\mathrm{p}<0.05$.

\section{Results}

\subsection{Acute toxicity results}

\subsubsection{Effect of acute oral administration of aqueous extract of Rauwolfia vomitoria on body weight}

No significant change was recorded in both male and female body weight of rats after oral administration of aqueous extract at a single dose of $2000 \mathrm{mg} / \mathrm{kg}$ as shown in Figure 1. 


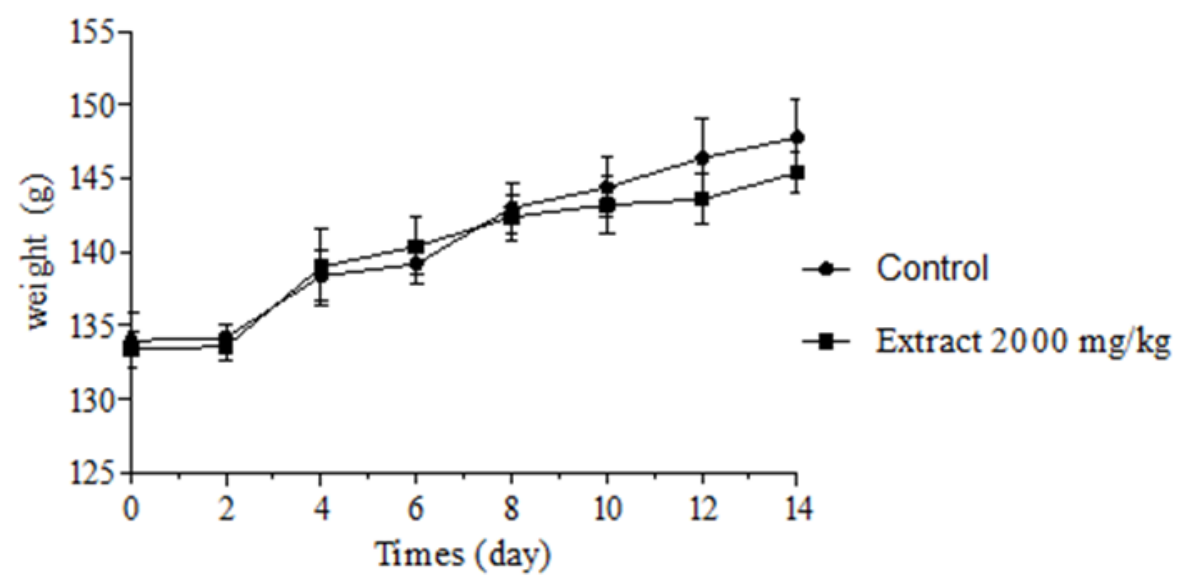

Figure 1 Effect of acute oral administration of aqueous extract of Rauwolfia vomitoria on body weight

Each point represented the average weight \pm E.S.M; $\mathrm{n}=5$.

\subsubsection{Effect of a single oral administration of aqueous extract of Rauwolfia vomitoria on mortality of rats}

No mortality was recorded during the 14 days of observation and the tested animals did not display any significant changes in weight of organs and behavioral pattern such as trembling, diarrhea, salivation, breathing, impairment in food intake, water consumption, postural abnormalities, hair loss, sleep, lethargy, restlessness, or in physical appearance such as eye colour, mucous membrane and skin effects when compared to control group.

\subsection{Sub-acute toxicity results}

\subsubsection{Effect of sub-acute oral administration of aqueous extract of Rauwolfia vomitoria on body weight}

In both male and female, the different doses of aqueous extract of $R$. vomitoria did not induce any significant difference of the body weight of rats when compared to control groups (Figure 2).

(a)
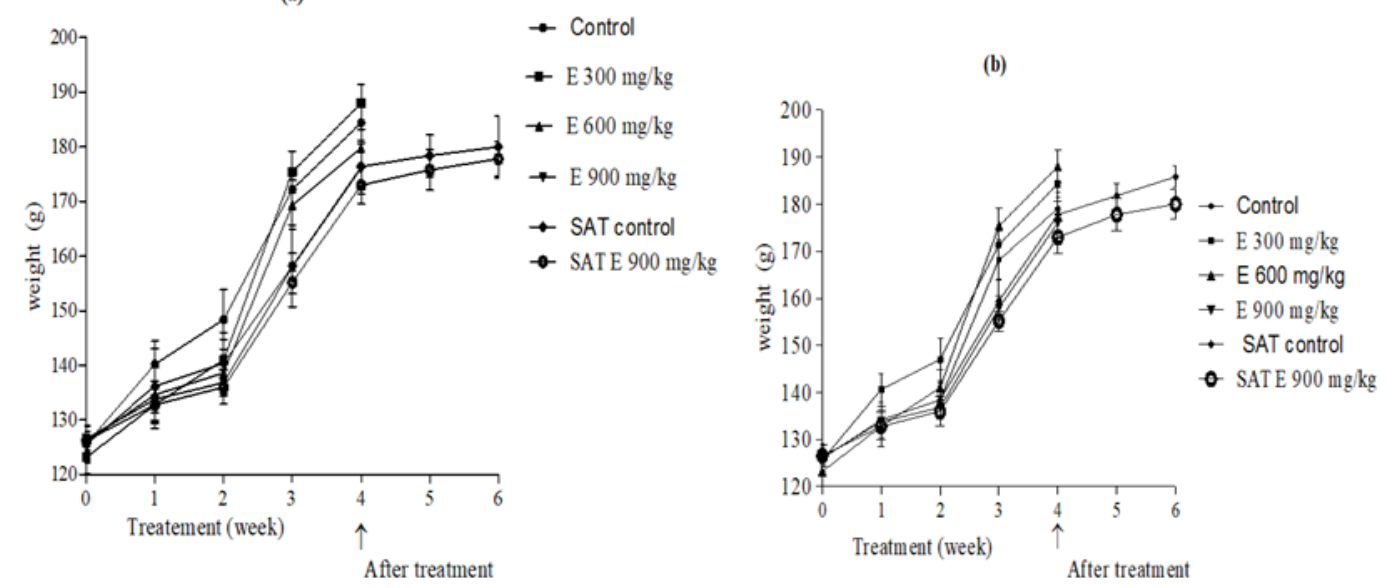

Figure 2 Potential effect of sub-acute oral administration of Rauwolfia vomitoria aqueous extract of on body weight, females (Fig 2a) and males (Fig 2b).

Each point represented the average weight \pm E.S.M; $n=5$;

E: Extract; SAT: Satellite ; SAT E: Satellite extract. 
3.2.2. Effect of sub-acute oral administration of aqueous extract of Rauwolfia vomitoria on water and food consumption and relative body weight organs

In same light, there was no significant increase in food and water consumption, relative organ weight (liver, kidney, heart, and lungs) even also observed animals for 2 week after treatment.

\subsubsection{Effects of oral administration of aqueous extract of $R$. vomitoria on some biochemical parameters}

Result about biochemical parameters obtained in this study are summarized in Table I. Biochemical analysis of hepatic function parameters revealed in treated rats with aqueous extract at the dose of $900 \mathrm{mg} / \mathrm{kg}$ a significant increase $(\mathrm{p}<0.05)$ in transaminase activity compared to the control group. In female rats, ASAT activity increased about $31.20 \%$ and ALAT about $37.20 \%$ compared to control group. In male rats, only ALAT activity increase significantly by 35.37 when compared to control group. No significant change was observed in female satellite (SAT) groups. In SAT E 900 $\mathrm{mg} / \mathrm{kg}$ male and female rats, protein levels increase significantly $(\mathrm{p}<0.05)$ about $31.87 \%$ and $33.33 \%$ respectively when compared to their SAT control groups. The total cholesterol level in female rats treated with aqueous extract 900 $\mathrm{mg} / \mathrm{kg}$ increase significantly $(\mathrm{p}<0.05)$ by $22.28 \%$ compared to control group. No significant increase in triglyceride (TGY), HDL and LDL-cholesteols was observed in female rats compared to control group. In male rats, there was observed a significant change $(21.44 \%, \mathrm{p}<0.05)$ in total cholesterol level at the dose of $900 \mathrm{mg} / \mathrm{kg}$ when compared to control group. The aqueous extract at any administered dose did not affect creatinine levels.

\subsubsection{Effects of the sub-acute of oral administration of aqueous extract of $R$. vomitoria on some hematological parameters}

Hematological analyses have revealed that in male rats that white blood cells significantly $(\mathrm{p}<0.05)$ increase by 52.20 $\%$, monocytes $(32.56 \%, \mathrm{p}<0.05)$ and granulocytes $(30.30 \%, \mathrm{p}<0.05)$ lymphocytes $(32.55 \%, \mathrm{p}<0.05)$ when compared to control at the dose of $900 \mathrm{mg} / \mathrm{kg}$. In male rats against, hemoglobin concentration has significantly $(\mathrm{p}<0.05)$ increased by $19.50 \%$ compared to control group at the dose of $900 \mathrm{mg} / \mathrm{kg}$. The level of blood platelets has considerably increased by $21.92 \%$ compared to control group. In SAT rats, no significant variation compared to SAT control. In female rats, granulocytes significantly increase by $30.35 \%$ compared to control group at the dose of $600 \mathrm{mg} / \mathrm{kg}$. Hematocrit has also considerably increased by $38.06 \%$ compared to control group. In female rats against, SAT E $900 \mathrm{mg} / \mathrm{kg}$ hematocrit level has significantly increased by $22.86 \%$ when compared to SAT control (Table II).

\subsubsection{Histopathological examination of liver due to oral administration of aqueous extract of $R$. vomitoria}

Figure 3 represented histological section of liver of rats after oral administration of aqueous extract. In control groups, the liver tissue presents a normal structure. Visible in the structure you can see centrolobular vein (CV), hepatocytes (HEP) arranged in rows and visible sinusoids capillaries (SC) (Figure $3 \mathrm{~A}$ and D). In male and female rats treated with the aqueous extract at the dose of $900 \mathrm{mg} / \mathrm{kg}$ were shown leukocyte (Leu) infiltration (Figure $3 \mathrm{~B}$ and E). SAT E 900 $\mathrm{mg} / \mathrm{kg}$ has shown a normal architecture (Figure $3 \mathrm{C}$ and $\mathrm{F}$ ). 
Table I Effect of the sub-acute of oral administration of aqueous extract of $R$. vomitoria on some biochemical parameters

\begin{tabular}{|c|c|c|c|c|c|c|}
\hline \multirow{3}{*}{ Biochemical parameters } & \multicolumn{6}{|l|}{ Treatments } \\
\hline & \multicolumn{6}{|c|}{ Female } \\
\hline & Control & $\mathrm{E} 300 \mathrm{mg} / \mathrm{kg}$ & $\mathrm{E} 600 \mathrm{mg} / \mathrm{kg}$ & $\mathrm{E} 900 \mathrm{mg} / \mathrm{kg}$ & SAT control & SAT E $900 \mathrm{mg} / \mathrm{kg}$ \\
\hline $\operatorname{ASAT}(\mathrm{U} / \mathrm{L})$ & $58.62 \pm 3.31$ & $62.73 \pm 4.35$ & $64.91 \pm 3.69$ & $76.91 \pm 4.01 \alpha$ & $77.61 \pm 4.30$ & $79,61 \pm 3,10$ \\
\hline $\operatorname{ALAT}(\mathrm{U} / \mathrm{L})$ & $46.59 \pm 3.16$ & $50.43 \pm 1.85$ & $51.21 \pm 4.92$ & $63.92 \pm 5.17 \alpha$ & $55.31 \pm 8.77$ & $66,54 \pm 2,61$ \\
\hline Alkaline Phosphatase (U/L) & $20.75 \pm 0.51$ & $21.87 \pm 0.41$ & $22.13 \pm 0.43$ & $23.54 \pm 0.53$ & $21.15 \pm 1.14$ & $24,59 \pm 1,59$ \\
\hline Total protein $(\mathrm{mg} / \mathrm{mL})$ & $7.32 \pm 0.29$ & $8.26 \pm 0.41$ & $6.55 \pm 0.27$ & $9.76 \pm 0.23 \alpha$ & $6.62 \pm 0.50$ & $8,73 \pm 0,18^{\varepsilon}$ \\
\hline Bilirubine (mg/ dL) & $1.02 \pm 0.04$ & $1.07 \pm 0.04$ & $1.10 \pm 0.03$ & $1.14 \pm 0.02$ & $1.08 \pm 0.06$ & $1,13 \pm 0,03$ \\
\hline Total cholesterol (mg/dL) & $63.87 \pm 3.11$ & $62.55 \pm 3.55$ & $57.40 \pm 3.63$ & $53.42 \pm 3.15^{\alpha}$ & $68.85 \pm 1.66$ & $69,54 \pm 2,55$ \\
\hline HDL-Cholesterol (mg/ dL) & $21.75 \pm 1.15$ & $21.29 \pm 0.72$ & $18.89 \pm 0.95$ & $17.62 \pm 1.32$ & $23.60 \pm 1.08$ & $24,15 \pm 0,70$ \\
\hline Triglyceride (mg/ dL) & $76.35 \pm 3.06$ & $69.94 \pm 4.63$ & $70.32 \pm 1.80$ & $73.87 \pm 3.66$ & $58.70 \pm 1.89$ & $63,98 \pm 4,01$ \\
\hline LDL-Cholesterol (mg/ dL) & $26.84 \pm 1.92$ & $27.27 \pm 1.17$ & $24.43 \pm 1.30$ & $21.02 \pm 1.44$ & $33.51 \pm 2.07$ & $32,59 \pm 2,10$ \\
\hline \multirow[t]{2}{*}{ Creatinine (mg/ dL) } & $0.65 \pm 0.02$ & $0.63 \pm 0.04$ & $0.67 \pm 0.02$ & $0.62 \pm 0.06$ & $0.63 \pm 0.02$ & $0,68 \pm 0,02$ \\
\hline & & & & Male & & \\
\hline ASAT (U/L) & $55.61 \pm 5.02$ & $67.96 \pm 4.17$ & $69.27 \pm 4.24$ & $75.28 \pm 3.37 \alpha$ & $72.32 \pm 3.30$ & $76,94 \pm 3,65$ \\
\hline $\operatorname{ALAT}(\mathrm{U} / \mathrm{L})$ & $64.91 \pm 2.73$ & $64.74 \pm 4.80$ & $67.79 \pm 4.75$ & $88.75 \pm 3.27$ & $64.56 \pm 2.96$ & $67,50 \pm 5,45$ \\
\hline Alkaline phosphatase (U/L) & $15.57 \pm 1.35$ & $20.23 \pm 0.87$ & $19.80 \pm 1.06$ & $19.93 \pm 0.47$ & $19.44 \pm 1.23$ & $20,62 \pm 1,47$ \\
\hline Bilirubine (mg/dL) & $1.13 \pm 0.02$ & $1.15 \pm 0.03$ & $1.15 \pm 0.02$ & $1.17 \pm 0.03$ & $1.14 \pm 0.03$ & $1,19 \pm 0,04$ \\
\hline Total protein $(\mathrm{mg} / \mathrm{mL})$ & $5.78 \pm 0.19$ & $6.51 \pm 0.22^{\alpha}$ & $5.50 \pm 0.21$ & $5.18 \pm 0.24$ & $5.42 \pm 0.20$ & $4,73 \pm 0,18$ \\
\hline Cholesterol total (mg/dL) & $74.97 \pm 2.73$ & $62.55 \pm 3.78$ & $64.20 \pm 2.68$ & $63.47 \pm 2.08^{\alpha}$ & $72.26 \pm 1.89$ & $71,24 \pm 4,05$ \\
\hline HDL-Cholesterol (mg/dL) & $25.24 \pm 0.84$ & $21.28 \pm 0.72$ & $21.42 \pm 1.45$ & $20.78 \pm 0.96$ & $25.50 \pm 1.12$ & $6,10 \pm 0,58$ \\
\hline Triglyceride (mg/dL) & $79.41 \pm 2.20$ & $72.49 \pm 2.57$ & $70.32 \pm 2.83$ & $73.87 \pm 3.66$ & $58.69 \pm 1.89$ & $58,88 \pm 3,13$ \\
\hline LDL-Cholesterol (mg/dL) & $33.85 \pm 1.45$ & $26.77 \pm 1.38$ & $28.72 \pm 2.14$ & $27.91 \pm 1.87$ & $35.03 \pm 2.04$ & $35,31 \pm 1,23$ \\
\hline Creatinine (mg/dL) & $0.47 \pm 0.04$ & $0.53 \pm 0.10$ & $0.45 \pm 0.04$ & $0.47 \pm 0.07$ & $0.49 \pm 0.04$ & $0,51 \pm 0,04$ \\
\hline
\end{tabular}

$\alpha p<0.05$ significantly different compared to control; $\varepsilon p<0.05$ significantly different compare to SAT control; ASAT: Aspartate amino transferase. ALAT : Alamine amino transferase; E: Extract; SAT: Satellite; HDL: « High density lipoprotein ». LDL: « Low density lipoprotein; 
Table II Effect of the sub-acute of oral administration of aqueous extract of $R$. vomitoria on hematological parameters

\begin{tabular}{|c|c|c|c|c|c|c|}
\hline & \multicolumn{6}{|l|}{ Treatment } \\
\hline & & & Female & & & \\
\hline Hematological parameters & Control & $\mathrm{E} 300 \mathrm{mg} / \mathrm{kg}$ & $\mathrm{E} 600 \mathrm{mg} / \mathrm{kg}$ & $\mathrm{E} 900 \mathrm{mg} / \mathrm{kg}$ & SAT control & SAT E $900 \mathrm{mg} / \mathrm{kg}$ \\
\hline White blood cells $\left(10^{3} / \mu \mathrm{L}\right)$ & $2.53 \pm 0.07$ & $2.62 \pm 0.05$ & $2.65 \pm 0.11$ & $2.75 \pm 0.08$ & $2.81 \pm 0.08$ & $2.92 \pm 0.03$ \\
\hline Lymphocytes $\left(10^{3} / \mu \mathrm{L}\right)$ & $1.34 \pm 0.11$ & $1.46 \pm 0.07$ & $1.27 \pm 0.06$ & $1.20 \pm 0.07$ & $1.25 \pm 0.04$ & $1.24 \pm 0.35$ \\
\hline Monocytes $\left(10^{3} / \mu \mathrm{L}\right)$ & $0.28 \pm 0.06$ & $0.27 \pm 0.05$ & $0.21 \pm 0.06$ & $0.20 \pm 0.07$ & $0.26 \pm 0.04$ & $0.24 \pm 0.04$ \\
\hline Granulocytes $\left(10^{3} / \mu \mathrm{L}\right)$ & $0.84 \pm 0.19$ & $0.70 \pm 0.08$ & $1.10 \pm 0.28$ & $0.90 \pm 0.24$ & $1.11 \pm 0.18$ & $1.30 \pm 0.26$ \\
\hline Red blood cells $\left(10^{6} / \mu \mathrm{L}\right)$ & $9.76 \pm 0.30$ & $9.56 \pm 0.29$ & $9.96 \pm 0.43$ & $10.16 \pm 0.29$ & $9.96 \pm 0.40$ & $10.56 \pm 0.48$ \\
\hline Hemoglobine (g/dL) & $10.08 \pm 0.74$ & $11.48 \pm 0.17$ & $11.38 \pm 0.23$ & $12.38 \pm 0.64$ & $12.38 \pm 0.64$ & $12.28 \pm 0.46$ \\
\hline Hematocrit (\%) & $34.68 \pm 1.78$ & $39.68 \pm 3.40$ & $44.68 \pm 1.23$ & $47.88 \pm 2.04$ & $38.48 \pm 1.09$ & $47.28 \pm 2.55$ \\
\hline \multirow[t]{2}{*}{ Platelets $\left(10^{3} / \mu \mathrm{L}\right)$} & $1.06 \pm 0.02$ & $1.08 \pm 0.02$ & $1.10 \pm 0.02$ & $1.10 \pm 0.04$ & $1.07 \pm 0.02$ & $1.06 \pm 0.02$ \\
\hline & & & Male & & & \\
\hline White blood cells $\left(10^{3} / \mu \mathrm{L}\right)$ & $6.13 \pm 1.42$ & $6.53 \pm 0.35$ & $8.73 \pm 0.79$ & $9.33 \pm 1.64^{\kappa}$ & $7.13 \pm 1.27$ & $8.73 \pm 1.08$ \\
\hline Lymphocytes $\left(10^{3} / \mu \mathrm{L}\right)$ & $1.72 \pm 0.60$ & $1.32 \pm 1.21$ & $1.52 \pm 1.13$ & $2.28 \pm 0.69^{\kappa}$ & $1.76 \pm 0.55$ & $3.88 \pm 0.16$ \\
\hline Monocytes $\left(10^{3} / \mu \mathrm{L}\right)$ & $0.82 \pm 0.04$ & $1.02 \pm 0.22$ & $0.92 \pm 0.04$ & $1.90 \pm 0.27^{\alpha}$ & $0.98 \pm 0.10$ & $1.10 \pm 0.28$ \\
\hline Granulocytes $\left(10^{3} / \mu \mathrm{L}\right)$ & $4.94 \pm 0.40$ & $4.14 \pm 0.79$ & $4.54 \pm 0.62$ & $6.54 \pm 0.83^{\alpha}$ & $7.34 \pm 0.75$ & $9.14 \pm 1.96$ \\
\hline Red blood cells $\left(10^{6} / \mu \mathrm{L}\right)$ & $6.56 \pm 0.64$ & $5.36 \pm 0.83$ & $6.96 \pm 1.07$ & $7.56 \pm 0.81$ & $6.89 \pm 0.83$ & $6.75 \pm 0.39$ \\
\hline Hemoglobine (g/dL) & $11.28 \pm 0.28$ & $13.08 \pm 1.08$ & $11.48 \pm 0.76$ & $13.48 \pm 1.78^{\alpha}$ & $11.88 \pm 0.43$ & $11.68 \pm 0.93$ \\
\hline Hematocrit (\%) & $41.28 \pm 2.21$ & $42.88 \pm 1.28$ & $41.48 \pm 2.75$ & $43.08 \pm 2.60$ & $36.28 \pm 1.35$ & $42.68 \pm 1.40$ \\
\hline Platelets $\left(10^{3} / \mu \mathrm{L}\right)$ & $3.33 \pm 0.02$ & $3.86 \pm 0.20$ & $3.66 \pm 0.38$ & $4.06 \pm 0.39^{\alpha}$ & $2.86 \pm 0.18$ & $3.86 \pm 0.36$ \\
\hline
\end{tabular}

Results are expressed as mean \pm E.S.M. $n=5$.The statistical analysis was performed on absolute data

Ap $<0.05$ et ${ }^{\wedge} \mathrm{p}<0.001$ significant different compared to control.

E: Extract. SAT E: Satellite of extract. SAT control: Satellite of control 

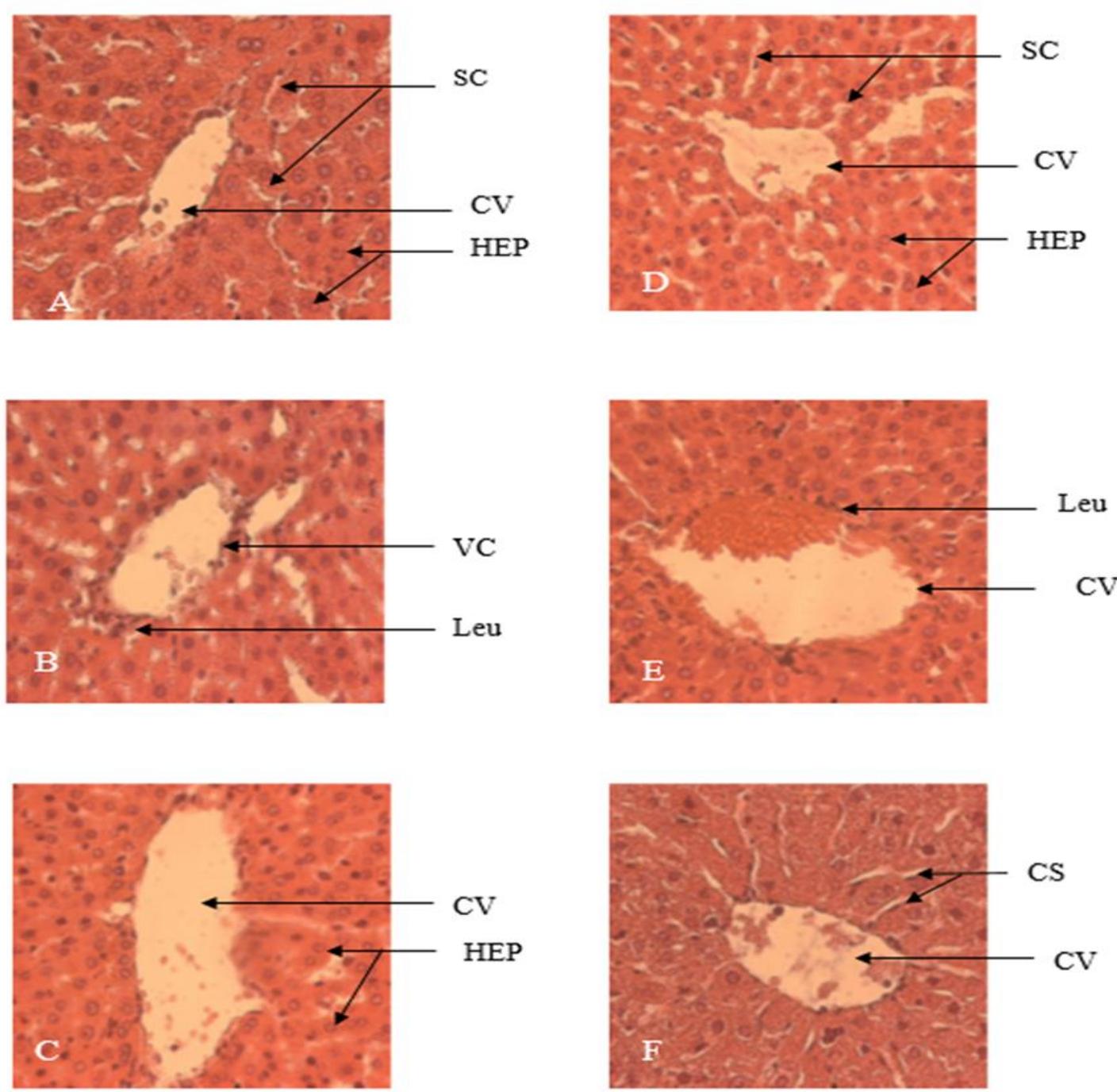

Figure 3 Microphotographs of liver structure of the aqueous extract of Rauwolfia vomitoria on hepatic morphological analysis in rats. Stained: hematoxylin eosin. Magnification: (x 400). Liver of male rats: control (A), treated rats at the dose of $900 \mathrm{mg} / \mathrm{kg}$ (B), satellite treated rats at the dose of $900 \mathrm{mg} / \mathrm{kg}$ (C). Liver of the female rats: control (D), treated rats at the dose of $900 \mathrm{mg} / \mathrm{kg}(\mathrm{E})$, satellite treated rats at the dose of $900 \mathrm{mg} / \mathrm{kg}(\mathrm{F})$.

CV: Centrolobular, HEP: Hépatocytes. SC: Sinusoid capillaries. Leu: Leukocyte infiltration.

\subsubsection{Histopathological examination of kidney due to oral administration of aqueous extract of R. vomitoria}

Histological section of the kidney of the rats is shown in Figure 4. The structure of the kidney tissue of the animals control group has presented a normal pattern showing proximal tubule (PT), distal tubule (DT), glomerulus (Gl), Bowman's capsule (BC) and urinary space (US) (Figure $4 \mathrm{~A}$ and D). The aqueous extract did not provoke any noticeable modification compared to control group (Figure $4 \mathrm{~B}$ and E). In satellite group (Figure $4 \mathrm{C}$ and F) no modification was observed compared to control group. 

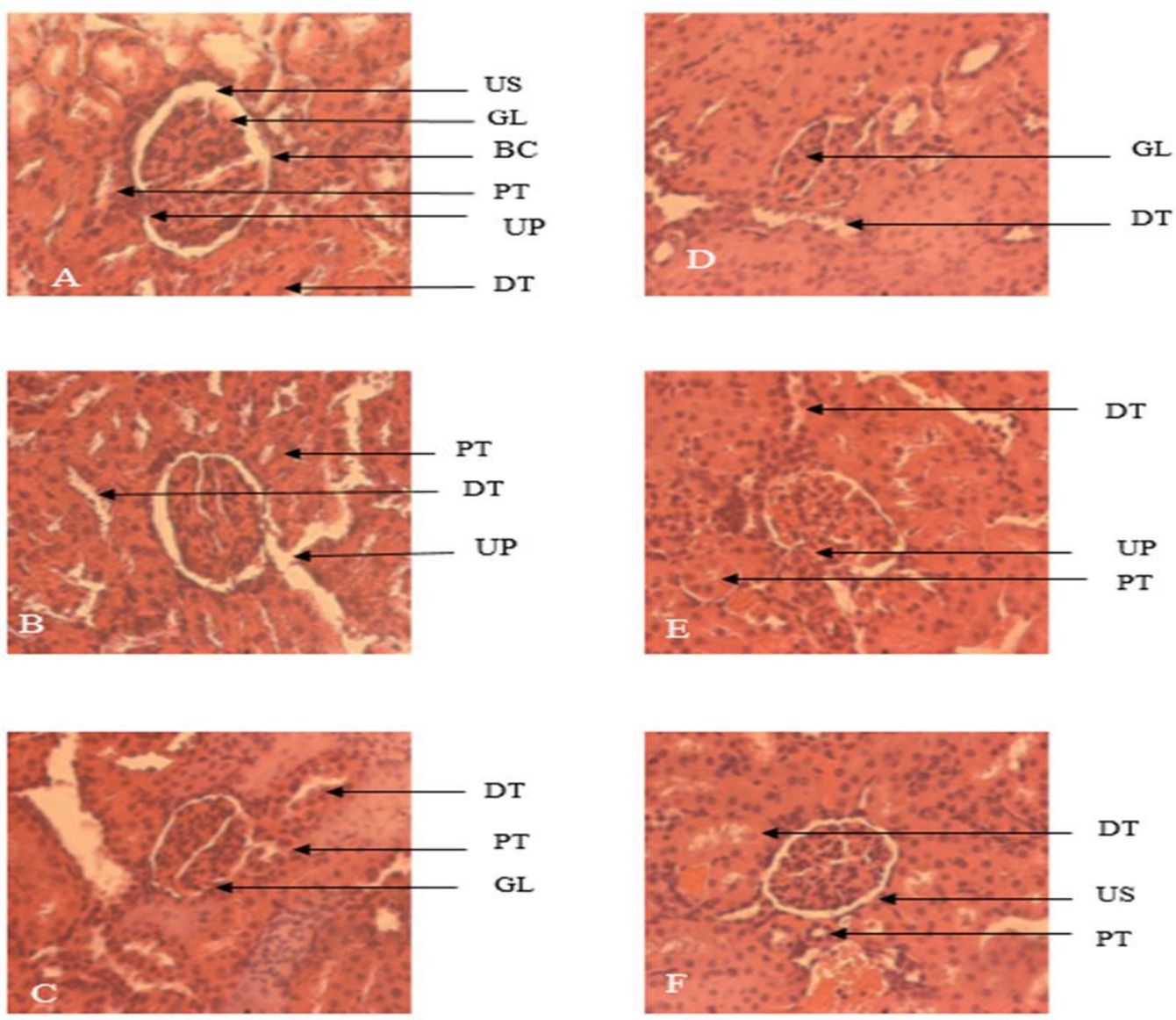

Figure 4 Microphotographs of kidney structure of the aqueous extract of Rauwolfia vomitoria on kidney morphological analysis in rats. Stained: hematoxylin eosin. Magnification: (x 400). Kidney of male rats: control (A), treated rats at the dose of $900 \mathrm{mg} / \mathrm{kg}$ (B), satellite treated rats at the dose of $900 \mathrm{mg} / \mathrm{kg}$ (C). Kidney of the female rats: control (D), treated rats at the dose of $900 \mathrm{mg} / \mathrm{kg}(\mathrm{E})$, satellite treated rats at the dose of $900 \mathrm{mg} / \mathrm{kg}(\mathrm{F})$.

PT: Proximal tubule; DT: Distal tubule; GL: Glomerulus; BC: Bowman's capsule; US: Urinary space; UP: Urinary pole.

\subsubsection{Histopathological examination of lungs due to the oral administration of aqueous extract of Rauwolfia vomitoria}

Figure 5 has shown histological section of the lung tissue of rats. The lung structure of the control group has presented a normal pattern with the alveolar sac (AS), alveoli (A), alveolar duct (AD) and blood vessels (BV) (Figure 5 A and D). The aqueous extract did not cause any change in structure of the lungs tissues when compared to control group (Figure $5 \mathrm{~B}$ and E). No structural alteration was observed in satellite rats compared to control group (Figure $5 \mathrm{C}$ and F). 

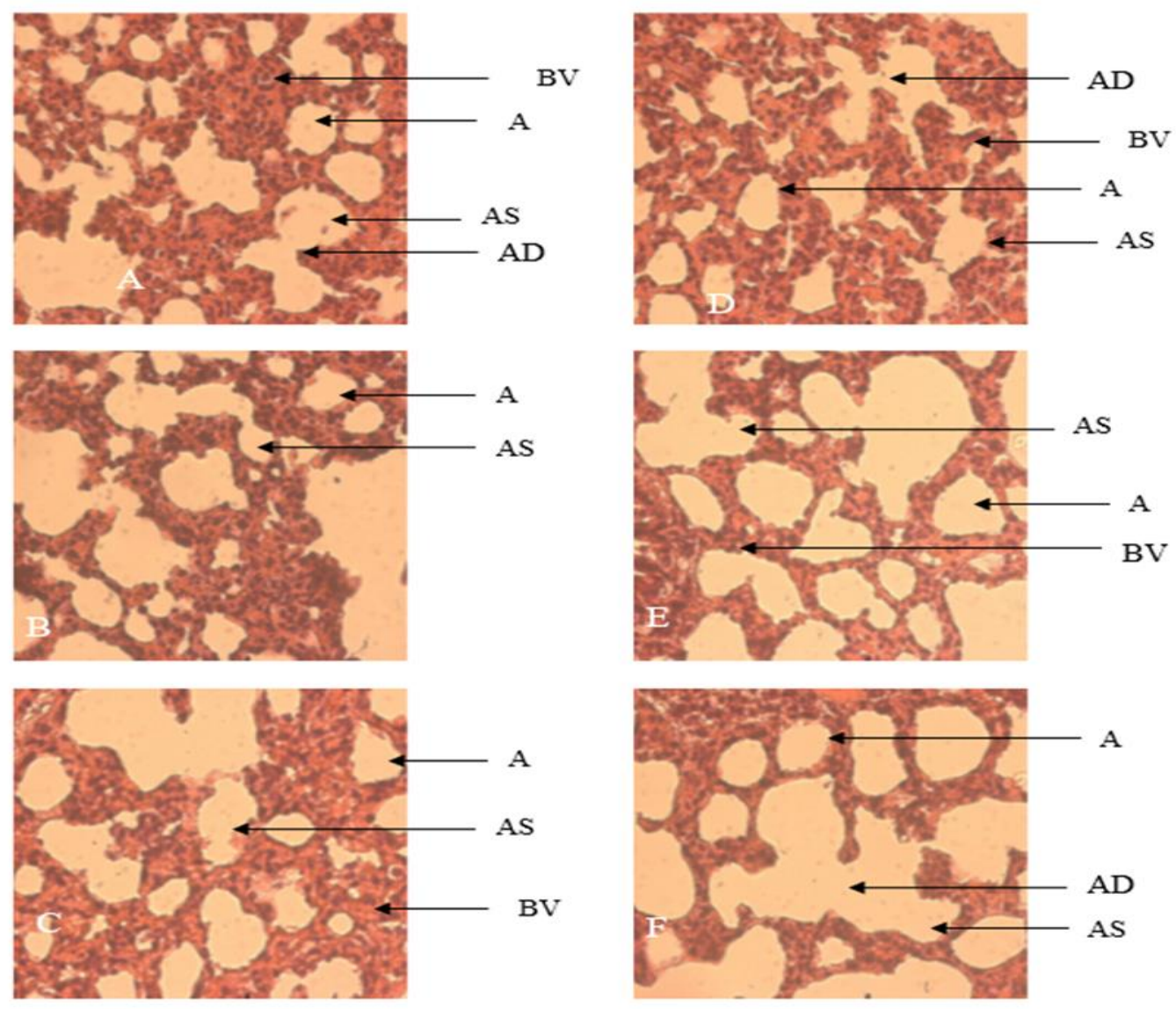

Figure 5 Microphotographs of lung structure of the aqueous extract of Rauwolfia vomitoria on lung morphological analysis in rats. Stained: hematoxylin eosin. Magnification: (x 400). Lung of male rats: control (A), treated rats at the dose of $900 \mathrm{mg} / \mathrm{kg}$ (B), satellite treated rats at the dose of $900 \mathrm{mg} / \mathrm{kg}$ (C). Lung of the female rats: control (D), treated rats at the dose of $900 \mathrm{mg} / \mathrm{kg}(\mathrm{E})$, satellite treated rats at the dose of $900 \mathrm{mg} / \mathrm{kg}(\mathrm{F})$.

AS: Alveolar sac. A: Alveoli. AD: Alveolar duct. BV: Blood vessels.

\section{Discussion}

Traditional medicines until date are mistakenly considered non-toxic because they are natural [16]. While, these natural products contain bioactive compounds that are capable to cause adverse effects [17]. Acute ant sub-acute toxicity of the aqueous extract of $R$. vomitoria was evaluated in rats.

The anthropometric parameters sometimes indicate the toxicity or adverse effects of natural products used as medicine [17]. Some of these parameters like weight of animals and organs, food and water consumption and behavioral pattern such as diarrhea, trembling, salivation and breathing carried out in this study did not display negative change. These results suggest that consumption of aqueous extract of $R$. vomitoria do not affect negatively growth system, digestive system and respiratory system in acute and sub-acute toxicities.

The study of acute toxicity of the aqueous extract of $R$. vomitoria showed that LD50 would be greater than $2 \mathrm{~g} / \mathrm{kg}$. Thus, making it classified in category 5 as Globally Harmonized classification System (GHCS) as relatively low toxic substances [18].

To identify the risks to human health after repeated consumption of the aqueous extract and following our previous pharmacological studies which showed that aqueous extract of $R$. vomitoria has an efficient dose of $300 \mathrm{mg} / \mathrm{kg}$ as antiinflammatory and anti-nociceptive properties [9] the doses of 300,600 and $900 \mathrm{mg} / \mathrm{kg}$ were used to perform sub-acute toxicity tests. Therefore, daily administration of aqueous extract at the various doses for 4 weeks showed no visible signs of intoxication during the observation period. 
Repeated administration of substance can cause adverse effects which may be reversible or irreversible, such as hepatotoxicity, nephrotoxicity, and neurotoxicity and pulmonary diseases [19, 20]. Repeated consumption of the aqueous extract of $R$. vomitoria for 28 days did not induce any significant change in food taken, water consumption, body weight and relative organ weights in rat of both sexes compared to the control group, suggesting that the aqueous extract would have no effect on these anthropometric parameters.

Serum biochemical analyses of rats treated with aqueous extract of $R$. vomitoria were evaluated to assess the effect of aqueous extract on hepatic markers, renal function and lipid profile. A significant increase in the usual markers of hepatic toxicity (ALAT and ASAT) was observed in rats of both sexes treated with the aqueous extract at the dose of 900 $\mathrm{mg} / \mathrm{kg}$ compared to control group. Transaminases (ALAT, ASAT) are enzymes known to be good indicators of liver function and as markers of possible toxicity [21]. Usually, damage of hepatocytes results in elevation of the level of these transaminase enzymes [21]. ALAT has its highest concentration in the liver and kidney while it is least in heart, brain and muscles [22]. ALAT activity is more specific than ASAT for liver function test and its activity is generally greater than ASAT activity in liver disease such as cirrhosis [23]. An increase in ALAT activity, however on the presence of an increase ASAT activity suggesting liver damage[24]. The increase levels of liver markers suggest that $R$. vomitoria aqueous extract may have impaired liver function and metabolism at the dose of $900 \mathrm{mg} / \mathrm{kg}$. As a result, the increase in activity of ALAT and ASAT transaminases in rats correlated with histological lesions (Leukocyte infiltration), suggesting a hepatotoxic potential of the aqueous extract of R. vomitoria at the dose of $900 \mathrm{mg} / \mathrm{kg}$. An increase of ALP reflects liver damage and obstruction of bile flow [24]. It is also known that ALP activity is elevated in many clinical conditions leads to bone and liver diseases. Its analysis is an important element to the correct diagnosis, screening and monitoring of hepatobilary lesions and osteoblastic bone diseases [25]. In the present study, the activity of alkaline phosphatase (ALP) in female rats has not changed significantly at the dose of $900 \mathrm{mg} / \mathrm{kg}$ compared to control rats, suggesting no action of aqueous extract on bile flow. The lipid profile (HDL-cholesterol, triglyceride and LDL-cholesterol) seems not to be affected by the oral administration of the aqueous extract of stem bark of $R$. vomitoria did not influence lipid metabolism.

In our study, complete blood count has been carried out, since the blood is one of the most important systems to scope out physiological heath status of human beings and animals [26]. In male rats, white blood cells number have increased in dose-dependent manner although the increased significant only at the dose of $900 \mathrm{mg} / \mathrm{kg}$. These results suggest that, the higher dose of aqueous extract may stimulate the production of leukocyte and/or stimulate defense cell blood. This can be explained by the fact of the relative toxicity of this dose of the extract observed with the effect of that dose in transaminase levels and lesions and leukocyte infiltration observed in liver tissues. Indeed, according to Adeneye et al., (2006) [25], therapeutic substances (Spondias pinnata and Musanga cecropioides) could have an action on hematopoietic differentiation cells. The number of lymphocytes in the group treated with aqueous extract at the dose of $900 \mathrm{mg} / \mathrm{kg}$ significantly increased in male rats. These results could be explained by the stimulation of B-lymphocytes by proliferation. The granulocyte cells are significantly elevated for the group treated with the aqueous extract at the same dose of $900 \mathrm{mg} / \mathrm{kg}$ in male rats. These results could be explained by the fact that granulocytes also called polynuclear cells are defense cells in the blood that have been activated by the aqueous extract of $R$. vomitoria. The hemoglobin and platelet concentration were significantly increased in rats treated with the aqueous extract at the dose of $900 \mathrm{mg} / \mathrm{kg}$ in male rats. These results suggest that the extract acts by stimulating erythroblast and megakaryoblast for the production of hemoglobin and blood platelets respectively. In female rats blood parameters did not change significantly, suggesting that the stimulation of hematopoietic cells by aqueous extract is related to sex.

Tissue histology can be used to detect pathologies related to organs. In the present study, histological sections of the kidneys and lungs showed no abnormalities in female and male rats. On the other hand, infiltration of inflammatory cells in liver shown in rats of both sexes treated with aqueous extract at the dose of $900 \mathrm{mg} / \mathrm{kg}$. This observation suggest that the aqueous extract at this dose could be toxic following repeated oral administration but, this action was reversible in this study after two weeks since the structure of the liver tissues of the rats of satellite groups were normal.

\section{Conclusion}

The oral administration of the aqueous extract of the stem bark of $R$. vomitoria was relatively non-toxic for acute or subacute toxicity. Nevertheless, some signs of toxicities were observed in sub-acute administration of aqueous extract at the highest dose $(900 \mathrm{mg} / \mathrm{kg})$ evidenced by leukocyte infiltration on the liver and increased transaminase activities. But, this adverse effects were reversible two weeks after the end of treatment. This is a proof that aqueous extract of Rauwolfia vomitoria is no toxic to human beings and animals. That could be the reason why $R$. vomitoria is principally used by traditional practitioners to treat many diseases. 


\section{Compliance with ethical standards}

\section{Acknowledgments}

This research was partially funded by Pr. Maurice Aurélien SOSSO, Rector of the University of Yaounde 1-Cameroon for encouragement and indeed, the authors wish to thank him for valuable financial assistance. The authors wish to thank also Mr. Takala Jean Claude, technician laboratory in faculty of medicine and biomedical science of University of Yaoundé 1 for his implication in histological realisation. The authors wish to thank also Mr. Michel Archange Fokam Tagne for accepting to revise this manuscript.

\section{Disclosure of conflict of interest}

Authors declare that, there is not conflict of interest associated with this publication.

\section{Statement of ethical approval}

Animals used in this study were handled, according to ethical guidelines of Cameroon National Veterinary Laboratory as referenced by the approval and heal control No 001/17 CCS/MINEPIA/RD-NW/DD-ME/SSV.

\section{References}

[1] Pousset JL. Medicinal plants used as source of raw material for the pharmaceutical industry, problems and prospects in, drug production from natural products, Adesina SK (ed) proceedings of the seventh international symposium, DRPU, OAU. Lfe. Nigeria. 1988; 37-41.

[2] WHO. Traditional medicine: potential and increased need. World Health Organization. 2002; 2: 1-6.

[3] Sofowora AE. Medicinal plants and traditional medicine in Africa 2nd Ed. Spectrum Book Ltd. Ibadan Nigeria 1993.

[4] Pousset JL. Rauwolfia alkaloids: New alkaloids from the leaves of Rauwolfia vomitoria Afz. Ann. Pharm. Fr. 1965; 12: 733-38.

[5] Petit GR, Pierson FH, Herald CL. Anticancer drugs from animals, plants, and microoganisme. John Wiley \& Sons, Inc. NY. 1994.

[6] Amole 00, Onabanjo AO. Antipyretic effect of Rauwolfia vomitoria in rabbits. Nigeria J Nat Prod Med. 1999; 3 : 36-39.

[7] Demis DL, Capodice JL, Gorroochum P. Katz AE, Bullyan R. Anti-prostate cancer activity of a ß-carboline alkaloid enriched extract from Rauwolfia vomitoria. Int. J. Oncol. 2000; 5: 1065-73.

[8] Oliver-Bever B. Medicinal plants in West Africa. Plant acting on cardiovascular system. J Ethnopharmacol. 1982; 5: $1-17$

[9] Youmbie DDB, Dzeufiet DPD, Nkengoua ZE, Mezui C, Dimo T. Anti-inflammatory and ant-nociceptive effects of the stem bark aqueous extract of Rauwolfia vomitoria (Apocynaceae). Wor J Pharm and Pharm Sci. 2015; 7: 90112.

[10] Youmbie DDB, Dzeufiet DPD, Nkwengoua E, Zingue S, Mezui C, Bibi FAO, Tankeu NF, Pieme CA, Dimo T. Antiinflammatory and antioxidant effects of the stem bark aqueous extract of Rauwolfia vomitoria in female wistar rats. Eur J Pham and Med Res. 2015; 7: 64-73.

[11] Principe P. In: Economic and medicinal research Vol. 3 (Wagner H. Hikino H, Farnsworth, NR (eds). Academic Press London. 1989; 1-17.

[12] Burkill HM. Useful plants of West Tropical Africa. Vol: 2 Families E-l, Royal Botanical Gardens, Kew. 1994.

[13] Waterman PG. A phytochemist in the African rain forest. Phytochem. 1986; 1: 3-17.

[14] Gornal AG, Bardawil GS, David MM. Determination of serum proteins by the mean of the buiret reactions. J Biol and Chem. 1949; 177: 751-66.

[15] OCDE. OECD Guidance Document on Acute Oral Toxicity Testing ; Oganization for Economic Co-operation and Development: Paris France. 2001. 
[16] Gesler WM. Therapeutic landscapes: medical issues in light of the new cultural geography. J Soc Sci Med. 1992; 34: 735-46.

[17] Bent S, Ko R. Commonly used herbal medicines in the United States: a review. American J Med. 2004; 116: 47885.

[18] OCDE. OECD guideline for testing of chemicals. Test No 407 : repeated dose 28- dayoral toxicity in rodents. Paris : OECD publishing. 2008; 4: 1-14.

[19] Lapointe G. Notions de Toxicologie. Commssion de la santé et de Sécurité du Travail du Quebec. 2004; 67-68.

[20] Duborija-Kovacevic N, Jakovljevic V, Sabo A, Tomic Z. One-month treatment with olive oil decreased the weight of spleen and increased the weight of prostate in Wistar rats. Frontiers in Pharmacology, Conference Abstract: 8th Southeast European Congress on Xenobiotic Metabolism and Toxicity-XEMET. 2010.

[21] Rahman MF, Siddigui MK, Jamil K. Effects of Vepacide (Azadirachta indica) on aspartate and alamine aminotransferase profiles in a subchronique study with rats. J Human Experimental Toxicol. 2001; 20: 243-49.

[22] Ringler DH, Dabich L. Haematology and Clinical Biochemistry. The Laboratory Rat. Academic Press London. 1979; 105-118.

[23] Mathieson PW, Williams G, MacSweeney JE. Survival after massive ingestion of carbon tetrachloride treated by intravenous infusion of acetylcysteine. Human Toxicol. 1985; 4: 627-31.

[24] Porchezhian E, Ansari SH. Hepatoprotective effects of Abutilon indicum on experimental liver damage in rats. J Phytomed. 2005; 12: 62-64.

[25] Adeneye AA, Ajagbonna OP, Adeleke TI, Bello SO. Preliminary toxicity and phytochemical studies of the stem bark aqueous extract of Musanga cecropioides in rats. J Ethnopharm. 2006; 105: 374-79. 